\title{
Mesonephric Remnants of the Prostate: Incidence and Histologic Spectrum
}

\author{
David G. Bostwick, M.D., M.B.A., Junqi Qian, M.D., Jun Ma, M.D., Trudie E. Muir, M.D. \\ Bostwick Laboratories, Richmond (DGB, JQ, JM) and The University of Virginia, Charlottesville (DGB), \\ Virginia; and the Department of Pathology, Deaconess Billings Clinic, Billings, Montana (TEM)
}

Mesonephric remnants in the prostate are an unusual mimic of adenocarcinoma with unknown incidence. This condition is considered benign, similar to its counterpart in the female genital tract, but there have only been six cases reported to date, so the histologic spectrum of this finding is uncertain. To determine the incidence and comparative histopathology of this finding, we reviewed all transurethral resections of the prostate obtained at Mayo Clinic (Rochester, MN) in 1989 to identify cases of mesonephric remnants. Among 698 prostatic transurethral resection specimens, we identified 4 cases of mesonephric remnants $(0.6 \%$ incidence), all in association with nodular hyperplasia. Patients ranged in age from 66 to 82 years (mean, 72 y) and had typical urinary obstructive symptoms; follow-up was obtained in these 4 cases. Four additional consultation cases and one needle biopsy case were also included in this study. Histologically, mesonephric remnants consisted of a proliferation of benign acini arranged in lobules or showing infiltrative growth between smooth muscle bundles without stromal desmoplasia. The acini were typically round or oval, varied in size and spacing, and lined by a single layer of low cuboidal cells with scant to moderate cytoplasm and inconspicuous small nucleoli. The cells of mesonephric remnants were not reactive with antibodies to prostatespecific antigen (eight of eight cases) or with prostatic acid phosphatase (seven of seven cases); high-

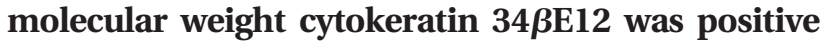
in the basal cells (six of eight cases). Our results indicate that mesonephric remnants are present in $<1 \%$ of transurethral resections and are rarely identified in needle biopsies. The acini are lobular or infiltrative and may be architecturally mistaken

Copyright (C) 2003 by The United States and Canadian Academy of Pathology, Inc.

VOL. 16, NO. 7, P. 630, 2003 Printed in the U.S.A.

Date of acceptance: March 6, 2003.

Address reprint requests to: David G. Bostwick, M.D., M.B.A., Bostwick Laboratories, 2807 N. Parham Rd., Richmond, VA 23294; fax: 804-2886568; e-mail: bostwick@bostwicklaboratories.com.

DOI: 10.1097/01.MP.0000074733.10777.78 for adenocarcinoma. This cytologically innocuous finding is probably underreported and interpreted as benign prostatic acini, but this is of no apparent clinical consequence. Immunohistochemical studies with antibodies to PSA and keratin 34BE12 are helpful in separating mesonephric remnants from adenocarcinoma, similar to the case of other benign mimics.

KEY WORDS: Atypical adenomatous hyperplasia, Incidence, Mesonephric, Nephrogenic, Nodular hyperplasia, Pathology, Prostatic adenocarcinoma, Prostatic tumors, Remnants.

Mod Pathol 2003;16(7):630-635

Mesonephric ducts are embryonic structures that are eventually replaced by metanephric ducts to form the permanent kidney. Mesonephric ducts play a critical role in the development of the functional urinary system and male reproductive system, including the ureter, renal pelvis, and collecting tubules, ejaculatory ducts, seminal vesicles, and ductus deferens. Embryonic vestiges of the ducts, mesonephric remnants, may persist after conversion of the ducts to the paramesonephric ducts. In females, mesonephric remnants form the epoophoron and paroophoron in the broad ligament and parametrical lateral to the uterus, cervix, and vagina. In males, mesonephric remnants form the appendix epididymis, although rarely, remnant acini are found in the renal pelvis (1), spermatic cord, vas deferens, and urethra (2); only six cases have been reported in the prostate and prostatic urethra (1-5).

Mesonephric remnants consist of small acini lined by benign cuboidal to low columnar epithelium. Mesonephric remnants are an uncommon differential diagnostic consideration among small acinar proliferations in the prostate; one reported case of mesonephric remnants with prominent nucleoli was misinterpreted as adenocarcinoma and resulted in radical prostatectomy (3). The incidence and comparative histologic spectrum of mesonephric remnants in the prostate has not been previ- 
ously reported because of the small number of cases identified to date. Herein we report our experience with MR of the prostate.

\section{MATERIALS AND METHODS}

Histologic slides from all transurethral resections of the prostate performed at the Mayo Clinic in 1989 were reviewed to identify cases of mesonephric remnants. Additionally, four cases from the consultation files of one of the authors (DGB) and one routine needle biopsy case were included for histologic comparison. The study protocol was approved by the Institutional Review Board of the Mayo Clinic (Rochester, MN).

Immunoperoxidase studies were performed on paraffin-embedded sections using the avidinbiotin-peroxidase method. Briefly, tissue sections were dewaxed, dehydrated, immersed in hydrogen peroxide $(0.6 \%)$ to quench endogenous peroxidase activity, and steamed in citrate buffer $(0.1 \mathrm{M}, \mathrm{pH}$ 6.0) for 30 minutes. The sections were rinsed in phosphate-buffered saline (PBS, pH 7.4) and overlaid with antibodies to keratin $34 \beta E 12$ (DAKO, Carpinteria, CA; dilution, 1/20), prostate-specific antigen (PSA; DAKO, 1/200), and prostatic acid phosphatase (PAP; DAKO, 1/400) for 45 minutes at room temperature. We used the avidin-biotinperoxidase method with 3,3'-diaminobenzidine (3,3'-diaminobenzidine) chromogen (DAKO Envison + System, DAKO). Positive and negative controls were run in parallel and yielded expected results. Clinical information was obtained through chart review and follow-up with pathologists and clinicians.

\section{RESULTS}

Among 698 transurethral resection specimens, 4 cases of mesonephric remnants ( $0.6 \%$ incidence) were identified. Patients ranged in age from 66 to 82 years (mean, $72 \mathrm{y}$ ), and all presented with typical urinary obstructive symptoms caused by nodular hyperplasia. Serum PSA concentration was available in 3 patients (Cases 1, 2, and 4) and ranged from 1.0 to $4.3 \mathrm{ng} / \mathrm{mL}$ (mean, $3.0 \mathrm{ng} / \mathrm{mL}$ ). All patients were alive without recurrence, with mean follow-up of 46 months (range, 5 to $87 \mathrm{mo}$ ).

Among 4 consultation cases, patients ranged in age from 50 to 80 years (mean, $65 \mathrm{y}$ ), and all presented with typical urinary obstructive symptoms caused by nodular hyperplasia. Serum PSA concentration and follow-up were not available.

The last case was a 67-year-old male with elevated serum PSA $(5.71 \mathrm{ng} / \mathrm{mL})$. Sextant biopsies were performed, and revealed benign prostatic tissue with focal mesonephric remnants.

\section{Pathologic Findings}

The greatest dimension of mesonephric remnants ranged from 0.1 to $0.7 \mathrm{~cm}$ (Table 1). The histologic features of prostatic mesonephric remnants were similar to those described in the uterine cervix (6-9), consisting of a proliferation of closely spaced acini arranged in lobules or infiltrating between muscle bundles and prostatic acini without a stromal desmoplastic response (Figs. 1, 2). Acini varied in size but were usually small; larger acini often contained eosinophilic colloid-like luminal material, a distinctive finding that was apparent at low-power magnification (Figs. 1, 2). Acini were

TABLE 1. Mesonephric Remnants of the Prostate, Prostatic Urethra, and Seminal Vesicles

\begin{tabular}{|c|c|c|c|c|}
\hline First Author & $\begin{array}{l}\text { Pt. Age } \\
\text { (yr) }\end{array}$ & $\begin{array}{l}\text { Remnants Size }(\mathrm{cm}) \text {, } \\
\text { Location }\end{array}$ & Immunophenotype & Other Features/Follow-Up \\
\hline Gikas, 1993 (3) & 65 & $\begin{array}{l}\text { Not provided (in } 10 \text { gram } \\
\text { TUR tissue) }\end{array}$ & PSA -. PAP-, Keratin 34 BE12 + & $\begin{array}{l}\text { Misinterpreted as adenocarcinoma, } \\
\text { resulting in radical prostatectomy }\end{array}$ \\
\hline Gikas, 1993 (3) & 64 & Not provided & PSA -. PAP-, Keratin 34 BE12 + & $\begin{array}{l}\text { Incidental finding in radical } \\
\text { prostatectomy }\end{array}$ \\
\hline Andersen, 1994 (1) & 63 & $\begin{array}{l}\text { Not provided (in } 5 \text { gram } \\
\text { TUR tissue) }\end{array}$ & PSA.- Pan - cytokeratin + & Incidental finding in TURP \\
\hline Val-Bernal, 1995 (4) & 66 & $\begin{array}{l}\text { Not provided (in } 12 \text { gram } \\
\text { of TUR tissue) }\end{array}$ & PSA -. PAP-, Keratin 34 BE12 - & Incidental finding in TURP \\
\hline Jimenez, 1998 (5) & 85 & Not provided & $\begin{array}{l}\text { PSA-. PAP }- \text {, Keratin } 34 \text { BE12, } \\
\text { S-100 -, Actin - }\end{array}$ & Incidental finding in TURP \\
\hline Jimenez, 1998 (5) & 50 & $\begin{array}{l}\text { Not provided (in } 53 \text { gram } \\
\text { radical prostatectomy) }\end{array}$ & PSA -. PAP - , Keratin $34 \mathrm{BE} 12+$, & $\begin{array}{l}\text { Incidental finding in radical } \\
\text { prostatectomy }\end{array}$ \\
\hline Bostwick, 2002 (Case 1) & 66 & $0.4 \times 0.3 \times 0.3$ & PSA -, PAP-, Keratin 34 BE12 + & Incidental finding in TURP \\
\hline Bostwick, 2002 (Case 2) & 77 & $0.4 \times 0.3 \times 0.3$ & PSA -, PAP-, Keratin 34 BE12 - & Incidental finding in TURP \\
\hline Bostwick, 2002 (Case 3) & 65 & $0.4 \times 0.3 \times 0.3$ & PSA - , PAP-, Keratin 34 BE12 + & Incidental finding in TURP \\
\hline Bostwick, 2002 (Case 4) & 82 & $0.7 \times 0.5 \times 0.5$ & PSA -, PAP-, Keratin 34 BE12 + & Incidental finding in TURP \\
\hline Bostwick, 2002 (Case 5) & 80 & $0.4 \times 0.2 \times 0.2$ & PSA -, PAP-, Keratin 34 BE12 - & Incidental finding in TURP \\
\hline Bostwick, 2002 (Case 6) & 62 & $0.5 \times 0.3 \times 0.3$ & PSA -, PAP-, Keratin 34 BE12 + & Incidental finding in TURP \\
\hline Bostwick, 2002 (Case 7) & 50 & $0.4 \times 0.3 \times 0.3$ & PSA -. PAP-, Keratin 34 BE12 + & Incidental finding in TURP \\
\hline Bostwick, 2002 (Case 8) & 66 & $0.6 \times 0.4 \times 0.3$ & Not Done & Incidental finding in TURP \\
\hline Bostwick, 2002 (Case 9) & 67 & $0.1 \times 0.1 \times 0.1$ & PSA -, Keratin 34 BE12 + & Incidental finding in needle biopsy \\
\hline
\end{tabular}


lined by a single layer of small- to medium-size cuboidal cells with scant amounts of eosinophilic or amphophilic cytoplasm (Figs. 1, 2). Nuclei were regular with finely dispersed chromatin and occasional small round punctuate nucleoli. No mitotic figures were identified, though mesonephric remnants in Cases 1, 2, 4, and 9 show hyperplastic features. The findings of mesonephric remnants were similar in needle biopsy and transurethral resection specimens.

\section{Immunohistochemical Findings}

Immunohistochemical studies were performed in 8 cases, including 4 Mayo cases, 3 consultation cases, and the needle biopsy case. The epithelial cells of mesonephric remnants showed no reactivity for PSA (8 cases) or PAP (7 cases). Six of 8 cases were moderately to strongly reactive in most of cells of mesonephric remnants with antibodies to highmolecular weight keratin 34ßE12 (Fig. 2). Adjacent benign prostatic epithelium in all cases served as internal positive controls and gave appropriate results.

\section{DISCUSSION}

We found that mesonephric remnants are a rare benign finding in the prostate, present in $<1 \%$ of transurethral resection specimens. Follow-up revealed no evidence of malignancy, although the number of cases was small and the interval limited. Nonetheless, the cumulative evidence from our nine cases and from six others reported in the literature (four in the prostate, one in the prostatic urethra, and one in the seminal vesicle) indicates that mesonephric remnants in the prostate and adjacent tissues are benign and of no clinical significance (Table 1). Recognition of this entity and its typical benign cytologic appearance (with rare exceptions) should allow separation from cancer; lack of PSA and PAP immunoreactivity provides additional support in equivocal or difficult cases (1-6). Immunohistochemistry demonstrated keratin $34 \beta \mathrm{E} 12$ reactivity in most mesonephric remnants cases. However, two of eight of our cases were negative for high-molecular weight keratin. Thus, the presence of high-molecular weight keratin is not a consistent finding in mesonephric remnants,
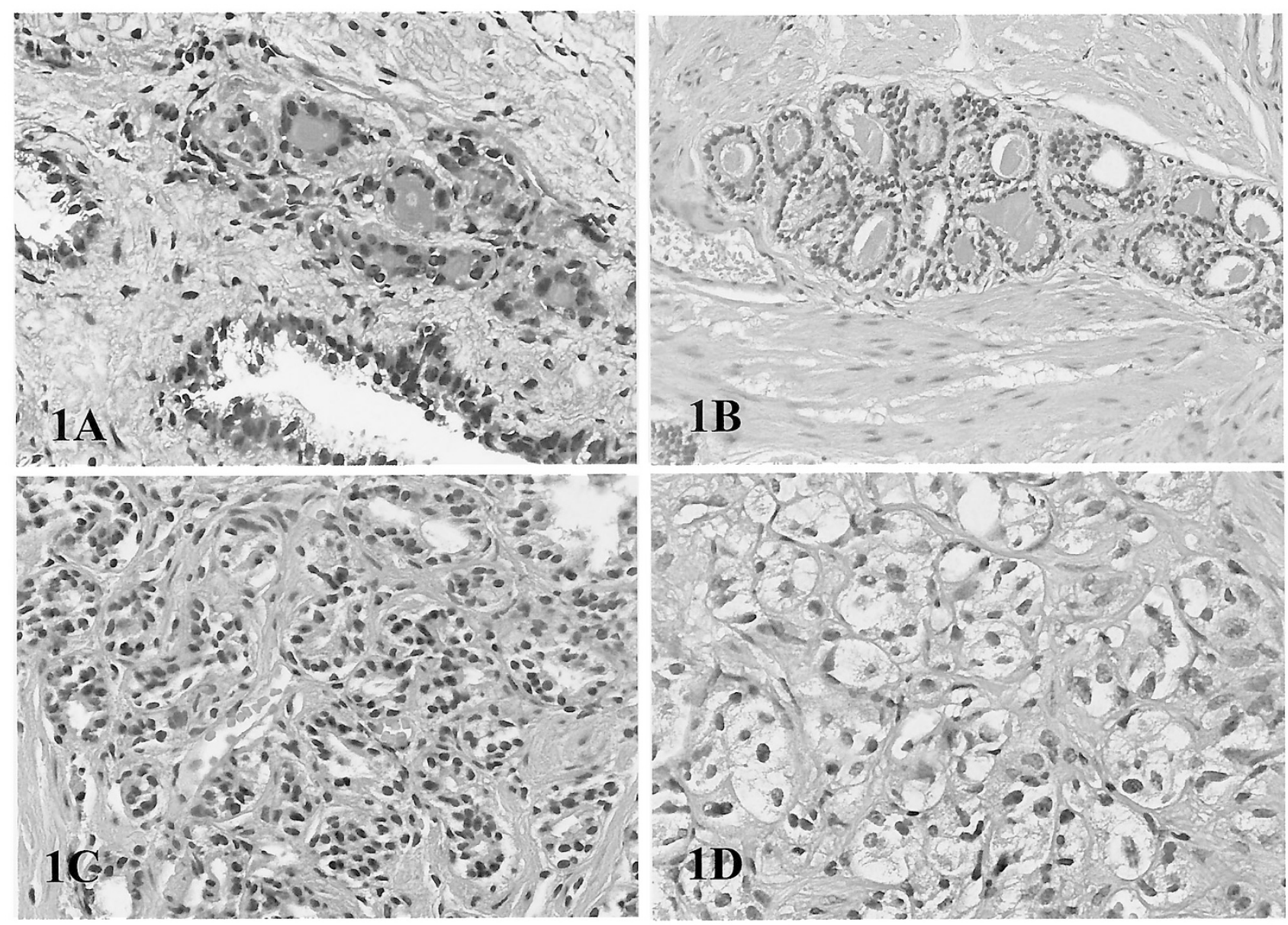

FIGURE 1. Histologic spectrum of mesonephric remnants. A, mesonephric remnants with closely spaced acini arranged in lobules in Case 9. B, mesonephric remnants with dilated tubules filled with an eosinophilic, colloid-like material in Case 1. C, mesonephric remnants with infiltrating growth pattern in Case 4. D, small, closely spaced mesonephric remnants acini with clear cytoplasm in Case 2. 

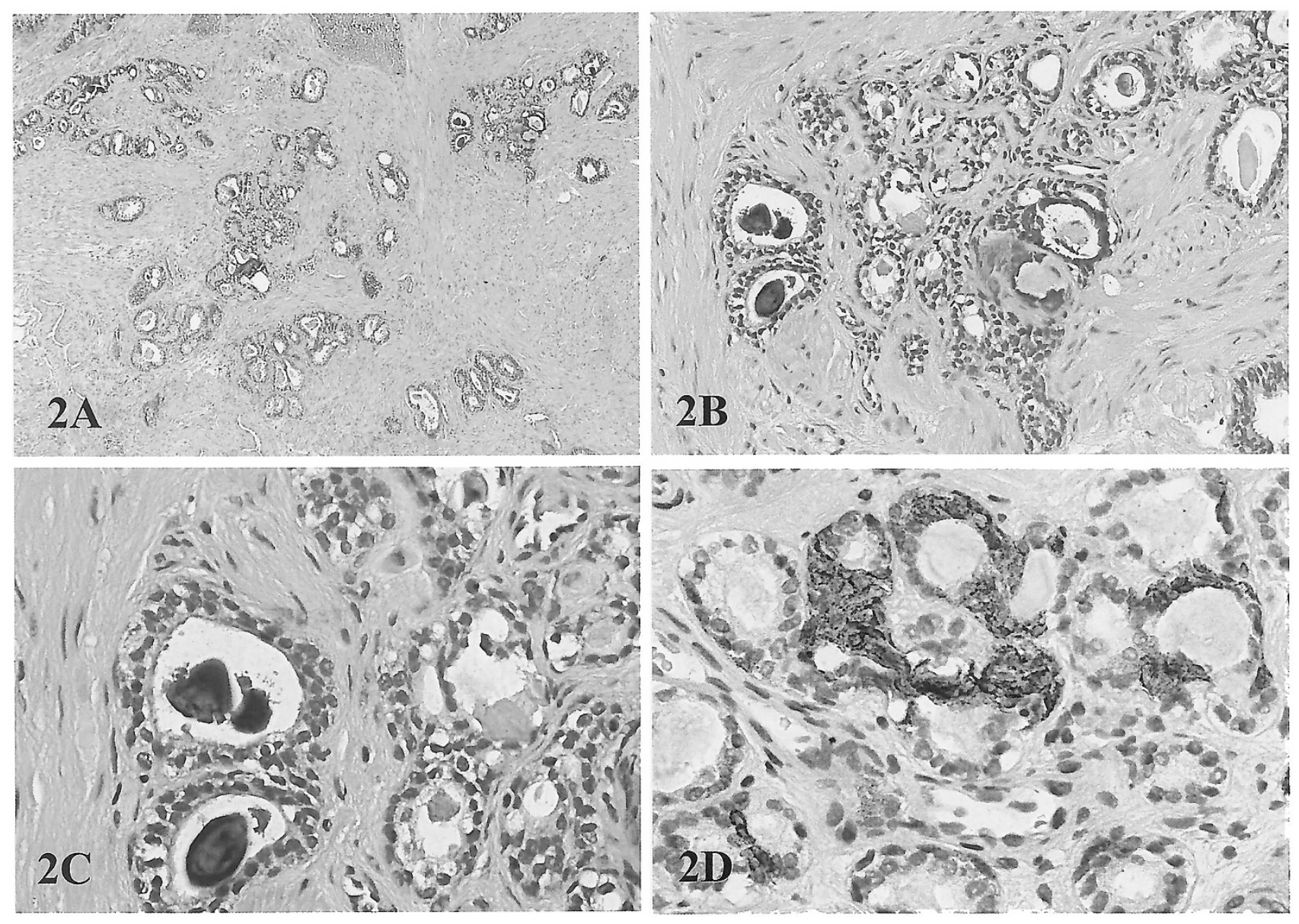

FIGURE 2. Mesonephric remnants in transurethral resection. A, mesonephric remnants consist of a proliferation of closely spaced acini arranged in lobules or infiltrating between muscle bundles without stromal response. B, some acini show dilated tubules filled with a eosinophilic, colloid-like material. C, high-power field shows acini lined by a single layer of small- to medium-size cuboidal cells with scant amounts of eosinophilic or amphophilic cytoplasm. D, immunohistochemistry reveals strong positive staining for high-molecular weight keratin (34 $\beta$ E12).

and this feature should not be used for the diagnosis of this entity.

In addition to cancer, mesonephric remnants should be distinguished from other benign small acinar proliferations of the prostate (10). Differential diagnostic considerations include atypical adenomatous hyperplasia, atrophy, postatrophic hyperplasia, basal cell hyperplasia, sclerosing adenosis, verumontanum mucosal gland hyperplasia, and atypical small acinar proliferation suspicious for but not diagnostic of malignancy. Atypical adenomatous hyperplasia is a localized proliferation of small acini without significant cytologic atypia that is usually found in intimate association with nodular hyperplasia (10). Unlike mesonephric remnants, atypical adenomatous hyperplasia displays a fragmented basal cell layer with keratin $34 \beta E 12$, as well as intense PSA and PAP immunoreactivity in the secretory cell layer (10).

Atrophy and its extreme form, postatrophic hyperplasia, may also be mistaken for mesonephric remnants, but both display at least focal PSA and PAP staining (11). Atrophy is a ubiquitous micro- scopic finding in the adult prostate, composed of small distorted glands with flattened epithelium, hyperchromatic nuclei, and stromal fibrosis. Postatrophic hyperplasia consists of a microscopic lobular cluster of 5 to 15 small acini with distorted contours reminiscent of atrophy. One or more larger dilated acini are usually present within these round to oval clusters, and the small acini appear to bud off of the dilated acinus. The small acini are lined by a layer of cuboidal secretory cells with mildly enlarged nuclei with an increased nucleusto-cytoplasmic ratio when compared with adjacent benign epithelial cells (11).

Another mimic of mesonephric remnants, basal cell hyperplasia, consists of a proliferation of basal cells that is 2 or more cells in thickness at the periphery of prostatic acini, often associated with chronic inflammation (12). The nests may be solid or cystically dilated and occasionally are punctuated by irregular round luminal spaces, creating a cribriform pattern. The lumens of basal cell hyperplasia may be empty or contain mucin or calcific 
debris; they lack the intensely eosinophilic proteinaceous secretions of mesonephric remnants (12).

Sclerosing adenosis of the prostate consists of a benign circumscribed proliferation of small acini set in a dense spindle cell stroma (13). The acini are predominantly well-formed and small to medium size but may form minute cellular nests or clusters with abortive lumens. The cells lining the acini display a moderate amount of clear to eosinophilic cytoplasm, often with distinct cell margins. The basal cell layer may be focally prominent and hyperplastic, particularly in acini thickly rimmed by paucicellular hyalinized stroma. In some areas, the acini merge with the exuberant stroma composed of fibroblasts and loose ground substance. There is usually no significant cytologic atypia of the epithelial cells or stromal cells, but some cases may show moderate atypia. Sclerosing adenosis can be distinguished from mesonephric remnants by its distinctive fibroblastic stroma, which is rarely seen in mesonephric remnants; hyalinized periacinar stroma occasionally seen in sclerosing adenosis; and immunophenotype of S-100 protein and actin immunoreactivity (13).

Verumontanum mucosal gland hyperplasia is another uncommon form of small acinar hyperplasia that mimics mesonephric remnants (14). It is invariably small, $<1 \mathrm{~mm}$; often multicentric; and limited anatomically to the verumontanum, utricle, ejaculatory ducts, and adjacent prostatic urethra and ducts. The acini are small and closely packed, with an intact basal cell layer and small uniform nuclei and inconspicuous nucleoli. The basal cells display immunoreactivity for high-molecular weight keratin and are S-100 protein negative. This lesion is rare in needle biopsies and is almost never sampled in transurethral resections because of the sparing of the verumontanum by this procedure (14).

In $\leq 2.5 \%$ of needle biopsies, there is a localized proliferation of small acini that is suspicious for carcinoma but falls below the diagnostic threshold (15-18). This problem is often caused by the small size of the focus. We have rarely diagnosed adenocarcinoma with as few as three malignant acini, and only when there was frank cytologic anaplasia that was in stark contrast with the adjacent benign epithelium; there was no inflammation or atrophy near the focus of concern, serial sections were obtained, and the possibility of seminal vesicle or ejaculatory duct epithelium was excluded. Other supportive evidence is useful, including patient age, serum PSA concentration, and keratin $34 \beta \mathrm{E} 12$ expression (16). Unlike mesonephric remnants, atypical small acinar proliferation displays intense PSA and PAP immunoreactivity in the secretory cell layer (15-21).
Adenocarcinoma arising in mesonephric remnants is a rare but recognized complication in the female genital tract (6-9); squamous cell carcinoma has also been rarely reported (6). Carcinoma has not thus far been reported in association with prostatic mesonephric remnants, but it may be difficult to histologically separate from acinar type prostatic adenocarcinoma without the use of immunohistochemical studies.

The anatomic location of mesonephric remnants in the prostate could not be determined in our study because of the nature (chiefly transurethral resection) of the specimens. However, based on the embryological location of the mesonephros and the tissue resected by TURP, we speculate that mesonephric remnants in the prostate are usually situated in a lateral periurethral/transition zone location. Similarly, studies of protein gene product 9.5 immunoreactivity in prostates from human embryos revealed apparent mesonephric tubular cells in the central prostate on the surface of the verumontanum and a small portion of the urogenital sinus (22).

Our study is limited by reliance on the lightmicroscopic features of mesonephric remnants for identification of cases as well as partial sampling of specimens and thus probably underestimates the true incidence of mesonephric remnants.

In summary, we found that mesonephric remnants are a histologically rare and immunohistochemically distinct finding in the prostate that should be distinguished from adenocarcinoma and other small acinar proliferations of the prostate.

\section{REFERENCES}

1. Andersen CB, Horn T, Rasmussen F, Larson S. Mesonephric remnants involving the renal pelvis and prostatic urethra. Scand J Urol Nephrol 1994;157:119-22.

2. Malpica A, Ro JY, Troncoso P, Ordonez NG, Amin MB, Ayala AG. Nephrogenic adenoma of the prostatic urethra involving the prostate gland: a clinicopathologic and immunohistochemical study of eight cases. Hum Pathol 1994;25:390-5.

3. Gikas PW, Del Buono EA, Epstein JL. Florid hyperplasia of mesonephric remnants involving the prostate and periprostatic tissue. Am J Surg Pathol 1993;17:454-60.

4. Val-Bernal JF, Gomez-Ortega JM. Hyperplasia of prostatic remnants: a potential pitfall in the evaluation of prostate gland biopsy. J Urol 1995;154:1138-9.

5. Jimenez RE, Raval MF, Spanta R, Sakr W, Grignon DJ. Mesonephric remnants hyperplasia. Pitfall in the diagnosis of prostatic adenocarcinoma. J Urol Pathol 1998;9:83-92.

6. Seidman JD, Tavassoli FA. Mesonephric hyperplasia of the uterine cervix: a clinicopathologic study of 51 cases. Int J Gynecol Pathol 1995;14:293-9.

7. Clement PB, Young RH, Keh P, Ostor AG, Scully RE. Malignant mesonephric neoplasms of the uterine cervix. A report of eight cases, including four with a malignant spindle cell component. Am J Surg Pathol 1995;19:1158-71.

8. Saito S, Higa I, Koyama Y, Hatano T, Hayakawa M, Osawa A, et al. Immature renal tissue in the inguinal canal. J Urol 1989;142:106-7. 
9. Smith CE, Toplia PJ, Nogales FF. Ovarian prostatic tissue originating from hilar mesonephric rests. Am J Surg Pathol 1999;23:232-6.

10. Bostwick DG, Qian J. Atypical adenomatous hyperplasia of the prostate. Relationship with carcinoma in 217 wholemount radical prostatectomies. Am J Surg Pathol 1995;19: 506-18.

11. Cheville JC, Bostwick DG. Postatrophic hyperplasia of the prostate. A histologic mimic of prostatic adenocarcinoma. Am J Surg Pathol 1995;19:1068-76.

12. Grignon DJ, Ro JY, Ordonez NG, Ayala AG, Cleary KR. Basal cell hyperplasia, adenoid basal cell tumor, and adenoid cystic carcinoma of the prostate gland: an immunohistochemical study. Hum Pathol 1988;19:1425-33.

13. Grignon DJ, Ro JY, Srigley JR, Troncoso P, Raymond AK, Ayala AG. Sclerosing adenosis of the prostate gland. A lesion showing myoepithelial differentiation. Am J Surg Pathol 1992;16:383-91.

14. Muezzinoglu B, Erdamar S, Chakraborty S, Wheeler TM. Verumontanum mucosal gland hyperplasia is associated with atypical adenomatous hyperplasia of the prostate. Arch Pathol Lab Med 2001;125:358-60.

15. Iczkowski KA, MacLennan GT, Bostwick DG. Atypical small acinar proliferation suspicious for malignancy in prostate needle biopsies: clinical significance in 33 cases. Am J Surg Pathol 1997;21:1489-95.

16. Potter SR, Horniger W, Tinzl M, Bartsch G, Partin AW. Age, prostate-specific antigen, and digital rectal examination as determinants of the probability of having prostate cancer. Urology 2001;57:1100-4.

17. Epstein JI, Potter SR. The pathological interpretation and significance of prostate needle biopsy findings: implications and current controversies. J Urol 2001;166:402-10.

18. Bostwick DG, Qian J, Frankel K. The incidence of high grade prostatic intraepithelial neoplasia in needle biopsies. J Urol 1995;154:1791-4.

19. Goldstein NS. Immunophenotypic characterization of 225 prostate adenocarcinomas with intermediate or high Gleason scores. Am J Clin Pathol 2002;117:471-7.

20. Brawer MK, Peehl DM, Stamey TA, Bostwick DG. Keratin immunoreactivity in the benign and neoplastic human prostate. Cancer Res 1985;45:3663-7.

21. Bostwick DG. Evaluating prostate needle biopsy: therapeutic and prognostic importance. CA Cancer J Clin 1997;47:297-319.

22. Aumuller G, Renneberg H, Leonhardt M, Lilja H, Abrahamsson PA. Localization of protein gene product 9.5 immunoreactivity in derivatives of the human Wolffian duct and in prostate cancer. Prostate 1999;38:261-7.

\section{Book Review}

\section{Schmidt RE, Reavill DR, Phalen DN: Pathology of Pet and Aviary Birds, 240 pp, Ames, IA, lowa State Press, 2003 (\$134.99).}

Pathology of Pet and Aviary Birds is a reference textbook based on a systems approach, providing summary descriptions of the major diseases of aviary birds. The book has both strengths and weaknesses. The major organ systems are covered. Strengths of the book include the discussion of normal anatomy at the start of each chapter and photography that ranges from good to excellent. Most of the major diseases are supported by gross or microscopic photographs. The primary weakness is that the organization by systems provides noncohesive coverage of the most important diseases in these species. Thus, the reader has to go to several chapters to gather relevant information about multisystem effects of individual diseases (polyomavirus, beak and feather syndrome, etc.), increasing the work of information recovery. Moreover, there is little organized discussion of actual disease pathogenesis. More information about the infectious agents, current agent classifications, modes of transmission, and pathogenetic mechanisms would have strengthened the book. Thus, it reads more like a disease atlas. It is a most useful book for filling a much needed gap in reference information on diseases of these species for working pathologists. The organization by systems and lack of cohesive and complete coverage of major diseases weaken the text as a teaching tool for veterinary students.

\section{David Pinson}

